\title{
Biphasic sonoelectrosynthesis. A review*
}

\author{
Jay D. Wadhawan, Frank Marken ${ }^{\S}$, and Richard G. Compton ${ }^{\ddagger}$ \\ Physical and Theoretical Chemistry Laboratory, Oxford University, South Parks \\ Road, Oxford OX1 3QZ, UK
}

\begin{abstract}
Electrosynthesis can be carried out in emulsions formed in situ via sonication of otherwise immiscible liquid/liquid systems. The basic physical principles underlying these experiments are introduced and illustrated via three examples: the electroreduction of liquid olefins, the Kolbe electrooxidation, and the electrogeneration of leuco-methylene green.
\end{abstract}

\section{INTRODUCTION}

Electrochemical processes are greatly affected when under conditions of insonation [1,2]. In homogeneous solutions, in addition to the vibration of each fluid particle in the acoustic field, there is a directed turbulent flow of material in the bulk solution, referred to as "acoustic streaming" [3-5]. This is one of the primary methods of material transport. When the sound transducer is located opposite the working electrode, acoustic streaming processes are often the dominant form of mass transport to the electrode [4]. In nonthermostatted cells, acoustic streaming processes can also increase the rate of heat transfer across the solution [3]. A second effect induced by ultrasound, often referred to as "cavitation", results from the emergence of voids generated by the rarefractive component of the longitudinal sound wave $[1,2,6,7]$, separating solvent molecules apart until the diameter of the void reaches approximately twice the van der Waals' radius of the solvent molecules [7]. At the solid/liquid interface, "cavitational collapse", evidenced by a pitting of the solid surface (and hence, increase in the roughness of the solid [8]), occurs. The mechanism by which it does so has been proposed to be via an asymmetric collapse of the cavities upon reaching the solid/liquid interface, primarily due to the difference in intermolecular forces between the solid and the liquid.

For the synthetic electrochemist, the employment of ultrasound under thermostatted conditions is beneficial, not only by causing fast rates of mass transport, but also via electrode activation: the cavitational phenomena can clean or depassivate surfaces [9] and lead to the possibility of in situ electrode activation [8]. A further advantage of ultrasound is that product distributions may be changed upon application of ultrasound [10,11]. Several reviews on ultrasound-assisted electrosynthesis (but exclusively under monophasic conditions) have appeared in the literature, and any interested reader is correspondingly directed toward these [12-15], in particular to ref. 12 .

The effect of ultrasound applied to liquid/liquid systems has been studied since 1927 [3,16-21]. In biphasic media, sonication results in the formation of an in situ emulsion, initiated by cavitational events at the liquid/liquid interface, with droplet size ca. $1 \mu \mathrm{m}$ (in fact, highly monodisperse emulsions can be achieved, with a mean particle size of $0.2-2.0 \mu \mathrm{m}$, and a size distribution range of $0.1-10 \mu \mathrm{m}$ or even narrower [3,21]). The degree of this "acoustic emulsification" process (see Fig. 1) is dependent upon a range of parameters, notably the ultrasonic power, the cell geometry and the chemical composition of the system; beyond a certain range of optimum conditions, ultrasound may cause the opposite effect, viz. coagulation and precipitation [19].

\footnotetext{
*An issue of reviews and research papers based on presentations made at the IUPAC/ICSU Workshop on Electrochemistry and Interfacial Chemistry in Environmental Clean-up and Green Chemical Processes, Coimbra, Portugal, 6-7 April, 2001.

${ }^{\ddagger}$ Corresponding author: E-mail: compton@ermine.ox.ac.uk; Tel.: +44 (0) 1865275 413; Fax: +44 (0) 1865275410

§Present address: Department of Chemistry, Loughborough University, Loughborough, Leicestershire LE11 3TU, UK
} 


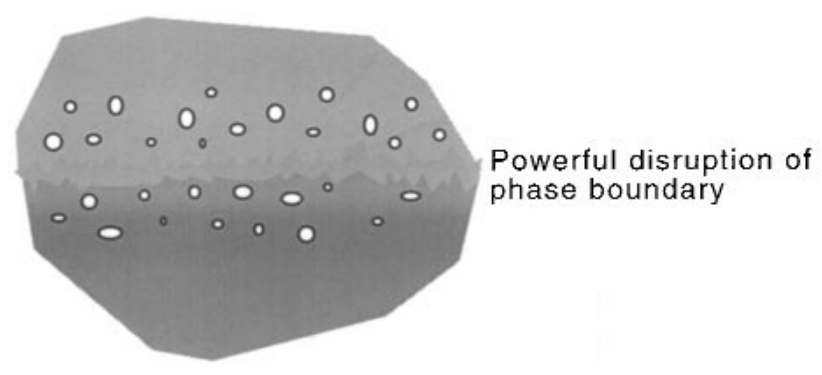

Fig. 1 The effect of sonication in a biphasic medium.

Recently [22], we have used acoustic emulsification to pioneer the development of "clean" and novel strategies for electrosynthesis [23-27] pari passu electroanalysis [28-31]. Electrosynthesis in emulsion media (stabilized by the use of surfactants) has been pioneered by Rusling and coworkers [32-34]. The purpose of this article is to illustrate sonoelectrosynthetic processes in biphasic media via reference to three case studies, the electroreduction of liquid olefins, the Kolbe electrooxidation, and the electrogeneration of leuco-methylene green (all emulsions formed using $20 \mathrm{kHz}$ power ultrasound).

There are generally two options by which the pursuit of sonoemulsion electrosynthesis may be achieved. The first involves suspending depolarizers as droplets in water, which under insonation are forcefully transported to the electrode surface by acoustic streaming processes. This may facilitate otherwise impossible electrochemistry [23]. This approach has the additional advantage that the "oil-inwater" emulsion that is produced provides a significant greening to an otherwise potentially environmentally unfriendly synthetic route, when compared to processes in nonaqueous solvents [35]. Furthermore, water is an ideal reaction environment for organic electrochemical processes, with good conductivity and polarity, and straightforward product isolation by extraction or filtration [36]. A second sonoemulsion electrosynthetic approach applies solely for the case of a solid electroactive compound, and consists of dissolving the depolarizer in a nonaqueous solvent, which is then emulsified with an aqueous solution as above. In this paper, we consider both methodological approaches.

The advantages of utilizing sonoemulsion media in which to undertake electrochemical synthesis include the following. First, the resulting emulsions are extremely stable [20], precluding the need for surfactants. It is believed that this stability is due to the monodisperse nature of the emulsions and to the formation of an electric double layer around the suspended droplets [3]. Second, the separation of products from the starting materials is facile: removing the acoustic field (by, for example, switching off the ultrasonic transducer) permits the separation of two immiscible phases. The organic phase is likely to contain the products of the electrosynthetic transformation, which can then be extracted and analyzed by conventional techniques. This method permits synthesis in the absence of environmentally unfriendly nonaqueous solvents. Third, there is a large surface area for electrochemical reactions to occur.

\section{INFLUENCE OF ULTRASOUND ON MASS TRANSPORT TO THE ELECTRODE IN ACOUSTIC EMULSION ENVIRONMENTS}

The application of ultrasound drastically increases the convective flux toward the electrode, due to a variety of factors as indicated in the Introduction, yielding sonovoltammograms containing sigmoidal waves, resembling typical hydrodynamic voltammograms produced from, for example, a rotating disc electrode $[37,38]$. The parameter that describes material transport in electrochemistry is the diffusion layer thickness, $\delta$. To explain the large mass transport, or correspondingly, the considerable decrease in the diffusion layer thickness, we need to consider inter alia (i) acoustic streaming, (ii) jets caused by cavitational collapse [39], (iii) turbulent convection, and (iv) microstreaming in the presence of oscillating bubbles [40]. 
The use of the diffusion layer thickness is based upon the diffusion layer model [1,2], which allows an approximate description of the mass transport at the electrode/solution interface by assuming a laminar sublayer close to the surface and an approximately linear concentration gradient across a thin layer adjacent to the electrode. Using these concepts, it is possible to use the following equation to describe mass transport,

$$
i_{\text {lim }}=\frac{n F A D c_{\text {bulk }}}{\delta}
$$

In this equation, $i_{l i m}$ is the limiting Faradaic current observed, and is related to the number of electrons transferred, $n$, the Faraday constant, $F$, the diffusion coefficient, $D$, the electrode area, $A$, the substrate concentration, $c_{b u l k}$, and the diffusion layer thickness. Although the applicability of this model is limited to certain types of sonoelectrochemical reactor and electrode geometry, it has been shown that eq. 1 is a good description when the electrode is placed opposite an ultrasonic immersion horn [1,2].

The above has considered mass transport processes in an insonated homogeneous solution. When a small quantity $(<50 \mathrm{vol} \%)$ of an electroinactive oil is coemulsified with a solution containing an electroactive depolarizer, the limiting current that is observed is similar to that in the absence of the oil, suggesting that eq. 1 is again valid under these conditions [22].

\section{ELECTROSYNTHESIS}

\section{Electroreduction of liquid olefins and alkynes}

The electrochemical reduction of unsaturated organic compounds to parafins is usually undertaken in nonaqueous solutions [41]. Here, we describe how this synthesis may be conducted in a more ecofriendly manner by using a sonoemulsion of the substrate in water, so eliminating the need for the nonaqueous solvent.

The electrochemical reduction of diethylmaleate, diethylfumarate, and diethylacetylene dicarboxylate in the form of microscopic droplets generated by applying power ultrasound to aqueous electrolyte media have been studied by Marken and coworkers [23]. Voltammograms for the reduction of the emulsions of these compounds in aqueous $1.0 \mathrm{M} \mathrm{MgCl}_{2}$ at a glassy carbon disc electrode were seen to be sigmoidally shaped signals, indicative of well-behaved responses, even at the very high rates of mass transport applied in the presence of ultrasound, corresponding to the general reactions:

$$
\begin{aligned}
& \mathrm{R}_{1} \mathrm{CH}=\mathrm{CHR}_{2}+2 \mathrm{H}^{+}+2 \mathrm{e}^{-} \rightarrow \mathrm{R}_{1} \mathrm{CH}_{2} \mathrm{CH}_{2} \mathrm{R}_{2} \\
& \mathrm{R}_{3} \mathrm{C} \equiv \mathrm{CR}_{4}+4 \mathrm{H}^{+}+2 \mathrm{e}^{-} \rightarrow \mathrm{R}_{3} \mathrm{CH}_{2} \mathrm{CH}_{2} \mathrm{R}_{4}
\end{aligned}
$$

Apparent diffusion coefficients were calculated from the voltammograms and are reported in Table 1. The determined diffusivity of diethylfumarate is somewhat smaller than that estimated for the hypothetical case of diethylfumarate dissolved homogeneously in water, however, the magnitude of the former suggests the ability of ultrasound to assist in the electrolysis of insoluble materials at efficiencies approaching those that would be accomplished if the substrates were soluble.

The comparison of the electrochemical reduction of dimethyl-, diethyl-, and dibutylmaleate emulsions in aqueous $1.0 \mathrm{M} \mathrm{MgCl}_{2}$ demonstrates the effect of the substrate solubility on the cathodic limiting currents; the increase in chain length of the organic depolarizer significantly alters the magnitude of the apparent diffusivity.

A plausible mechanism is:

$$
\begin{aligned}
& \mathrm{A}(\text { oil }) \rightleftarrows \mathrm{A}(\text { solution }) \\
& \mathrm{A}(\text { solution })+2 \mathrm{e}^{-}+2 \mathrm{H}^{+} \rightarrow \mathrm{B}(\text { solution }) \\
& \mathrm{B}(\text { solution }) \rightleftarrows \mathrm{B}(\text { oil })
\end{aligned}
$$


Table 1 Sonovoltammetric data for the reduction of $10 \mathrm{~mL}$ insoluble organic compound emulsified in $20 \mathrm{~mL}$ aqueous $1.0 \mathrm{M} \mathrm{MgCl}_{2}$ in the presence of $150 \mathrm{~W} \mathrm{~cm}^{-2}$ ultrasound. Voltammograms obtained at $298 \mathrm{~K}$, scan rate $0.1 \mathrm{Vs}^{-1}$, at a $3 \mathrm{~mm}$ diameter glassy carbon disc electrode.

\begin{tabular}{|c|c|c|c|c|c|c|}
\hline Compound & $\begin{array}{c}E_{1 / 2} / \\
\text { V vs. SCE }\end{array}$ & $\begin{array}{c}\text { Number } \\
\text { of electrons }\end{array}$ & $\begin{array}{c}10^{3} c_{\text {total }} / \\
\mathrm{M}\end{array}$ & $i_{l i m}{ }^{\prime}$ & $\begin{array}{l}10^{9} D_{\text {sol }} l \\
\mathrm{~m}^{2} \mathrm{~s}^{-1}\end{array}$ & $\begin{array}{l}10^{9} D_{\text {calc }} \\
\mathrm{m}^{2} \mathrm{~s}^{-1}\end{array}$ \\
\hline Diethylfumarate & -1.16 & 2 & 3.0 & 1500 & 0.61 & 0.58 \\
\hline Dimethylmaleate & -1.34 & 2 & 4.0 & 2500 & 0.73 & 0.73 \\
\hline Diethylmaleate & -1.23 & 2 & 3.1 & 1050 & 0.61 & 0.39 \\
\hline $\begin{array}{l}\text { Dibutylmaleate } \\
\text { Diethylacetylene }\end{array}$ & -1.24 & 2 & 2.2 & 180 & 0.50 & 0.09 \\
\hline $\begin{array}{l}\text { Dicarboxylate } \\
\text { Cyclohex-2-en-1 }\end{array}$ & -1.28 & 4 & 3.0 & ca. 500 & 0.6 & 0.20 \\
\hline -one & -1.58 & 2 & 5.2 & ca. 1700 & 0.83 & 0.38 \\
\hline
\end{tabular}

$E_{1 / 2}$ corresponds to the half-wave potential for sigmoidal responses. An empirical expression introduced by Wilke and Chang [42] allows the diffusivity, $D_{\text {sol }}$, to be estimated to within $\pm 10 \%$ accuracy. The observed diffusivity, $D_{\text {calc }}$, has been calculated assuming an homogeneous solution based on eq. 1, and using the approximate diffusion layer thickness of $1.6 \mu \mathrm{m}$.

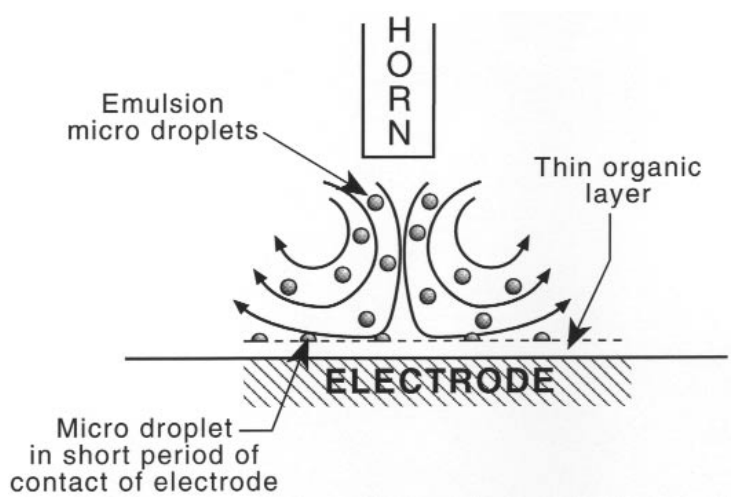

Fig. 2 Schematic representation of the thin film and droplet deposits that govern the sonovoltammetric response for electrochemical processes in acoustic emulsion systems.

in which the terms "A" and "B" refer to the olefin and the electrogenerated paraffin, respectively. Under insonation, the oil microdroplets droplets penetrate into the Nernst diffusion layer at the electrode surface and act as a local source of the depolarizer (Fig. 2).

This example illustrates the use of sonoemulsion conditions in permitting the electroreduction of several compounds that have only previously been undertaken in nonaqueous solvents [41]; this represents a significantly more clean electrosynthetic route that might otherwise be unattractive in comparison with conventional methodologies.

\section{Sonoemulsion Kolbe electrosyntheses}

The use of emulsified media together with the application of ultrasound may produce significant changes in product formation in comparison with monophasic electrochemistry: in a biphasic medium, there is the possibility of "trapping" the products and intermediates formed during Faradaic electrolysis in one phase, so modifying the electrochemical reaction mechanism, and thus the products. In this section, we examine the effect of an acoustic emulsion upon the Kolbe electrolysis. 
The Kolbe reaction is the electrosynthesis of hydrocarbons via electrooxidation of carboxylic acids [43]. Until now, Kolbe electrosyntheses under monophasic conditions have mainly been studied [44], yielding a general mechanism shown in Fig. 3a. At platinum anodes, the products that are formed from model compounds (e.g., butyric acid), tend to be described as "one-electron" products: the Kolbe dimer, the alkane, and the alkene (see Fig. 3a) [43]. In contrast, "two-electron" products tend to be formed at carbon-based anodes after formation of the carbocation, viz. the ester, the alcohol, and the alkene [43]. Ethers, produced by the nucleophilic attack of $\mathrm{RO}^{-}$on the carbocation may also be formed at carbon anodes if aqueous alcohol (ROH) is used as the solvent.

Novel biphasic Kolbe galvanostatic electrosyntheses were undertaken at both platinum and boron-doped diamond electrodes, the latter to minimize cavitation-induced damage of the anode surface $[26,27]$. Two liquid aliphatic acids, hexanoic and heptanoic acids, were investigated as model compounds that undergo Kolbe reactions. Each acid was emulsified with aqueous $1.0 \mathrm{M} \mathrm{NaOH}$, and after the passage of one-Faraday-per mole charge $\left(\mathrm{ca} .1500{ }^{\circ} \mathrm{C}\right)$, the reaction was quenched and the products analyzed using GC/MS and ${ }^{1} \mathrm{H}$ NMR (see Table 2).

The dimer yield was found to depend upon the reaction temperature, the aqueous electrolyte concentration (and thus conductivity of the sonoemulsion), and amount of charge passed; the maximum observed yield was found to be $75 \%$ (comparable to monophasic electrolyses), with a current efficiency of $45 \%$, at platinum electrodes. Additionally, only one side product can be observed (in a yield typically less than 5\%): the ester, amyl caproate (from hexanoic acid electrolysis), or capryl enanthoate (from the electrolysis of heptanoic acid). The fact that no other side products are formed suggests that $\mathrm{R}^{+}$(the carbocation formed following from a two-electron oxidation) or $\mathrm{R}^{\bullet}$ (the radical formed from a

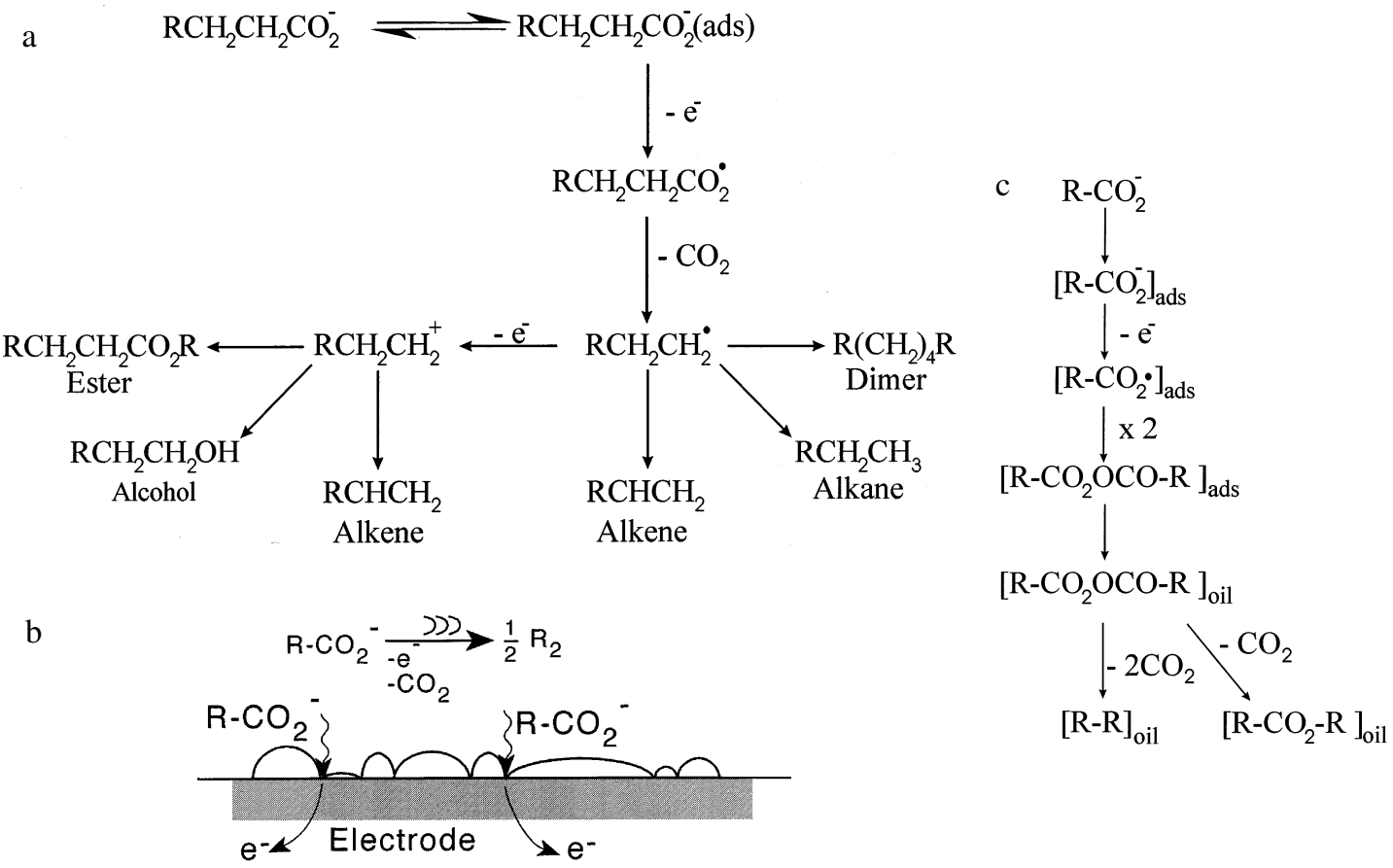

Fig. 3 (a) Scheme for Kolbe electrooxidation processes in purely monophasic systems. (b) Schematic drawing of the conditions during the formation of an insoluble product (organic deposits shown in grey) at the electrode surface under sonoemulsion reaction conditions. (c) Proposed reaction scheme for the sonoemulsion Kolbe electrosynthesis. 
Table 2 Results from galvanostatic electrolysis experiments from the oxidation of hexanoic or hepanoic acids at a $1.1 \mathrm{~cm}^{2}$ platinum anode (or at a $0.25 \mathrm{~cm}^{2}$ free-standing polycrystalline boron-doped CVD diamond electrode) when emulsified with aqueous $\mathrm{NaOH}$ using power ultrasound ( $190 \mathrm{~W} \mathrm{~cm}^{-2}, 7 \mathrm{~mm}$ horn-to-electrode separation). Charge equivalent to 1 Faradayper-mole of carboxylic acid was passed before analysis (ca. $1500^{\circ} \mathrm{C}$ ).

\begin{tabular}{lcccc}
\hline $\begin{array}{l}\text { Starting } \\
\text { material }\end{array}$ & $\begin{array}{c}{[\mathrm{NaOH}]} \\
/ \mathrm{M}\end{array}$ & $\begin{array}{c}\text { Current density } \\
/ \mathrm{A} \mathrm{cm}^{-2}\end{array}$ & $\begin{array}{c}\mathrm{T} \\
/ \mathrm{K}\end{array}$ & $\begin{array}{c}\text { Yield of } \\
\text { dimer/\% }\end{array}$ \\
\hline $1.1 \mathrm{~cm}^{2}$ Platinum disc electrode & & & & \\
1.72 g Hexanoic acid & 1.0 & 0.08 & 293 & 0 \\
1.72 g Hexanoic acid & 1.0 & 0.13 & 293 & $24 \pm 3$ \\
1.83 g Hexanoic acid & 1.0 & 0.18 & 293 & $45 \pm 5$ \\
1.82 g Hexanoic acid & 1.0 & 0.35 & 293 & $40 \pm 5$ \\
1.67 g Hexanoic acid & 0.1 & 0.18 & 293 & $17 \pm 2$ \\
1.87 g Hexanoic acid & 1.0 & 0.18 & 313 & $3 \pm 1$ \\
2.0 g Heptanoic acid & 1.0 & 0.18 & 293 & $15 \pm 2$ \\
2.0 g Heptanoic acid & 1.0 & 0.35 & 293 & $6 \pm 2$ \\
& & & & \\
$0.25 \mathrm{~cm}^{2}$ Diamond electrode & & & 293 & $40 \pm 5$ \\
$1.8 \mathrm{~g}$ Hexanoic acid & 1.0 & 0.35 & 293 & $14 \pm 5$ \\
1.80 g Hexanoic acid & 1.0 & 0.70 & & \\
\hline
\end{tabular}

single electron transfer process) are formed in a non-ion-conducting organic phase adjacent to the electrode surface (Fig. 3b). A possible reaction mechanism is given in Fig. 3c [27].

The products observed in conventional Kolbe electrolyses suggest that the electrode material exerts a strong control, with products predominantly derived from carbocation intermediates detected at carbon anodes [43]. Surprisingly, electrosynthesis at a boron-doped CVD diamond electrode under acoustic emulsification conditions again gives rise to the detection of predominantly the Kolbe dimer (see Table 2). Current efficiencies and yields are only slightly lower than those observed at platinum electrodes. Interestingly, the ester is again the sole by-product, suggesting that a mechanism similar to that at platinum electrodes is operative. The contrast with the results normally observed under monophasic conditions is clear, by the absence of the "switch" in mechanistic pathway by changing the anode material. The formation of nearly exclusively "one electron" products in this biphasic reaction medium may be rationalized by the reaction intermediates being trapped in a non-ion-conducting organic phase and further reactions at the electrode surface prevented (see Fig. 3c). The formation of a hydrophobic material such as decane or dodecane at the electrode surface gives rise to an organic deposit (see Fig. 3b) that is continuously removed in the presence of ultrasound.

The use of sonoemulsion conditions here, thus, has lead to the availability of a new mechanistic pathway for an organic electrode reaction, by encapsulation of the reaction intermediates within the organic phase of the electrolytic system.

\section{Electrosynthesis of leuco-methylene green}

The passivation of electrode surfaces by the products of a Faradaic process is a generic problem with electrosynthetic processes: many otherwise attractive electrosynthetic reactions are precluded by this problem [45]. In this section, we show how, by emulsifying a suitable solvent with aqueous electrolyte, it is possible to retain electrode activation, by "product trapping" in the organic phase of the oil-in-water emulsion.

leuco-Methylene green is a model for dyes used in the textile industry and can be formed via the electroreduction of methylene green (see Fig. 4a) [46-48]. In quiescent solution at platinum electrodes, 
insoluble $l$-methylene green coats the electrode surface, as evidenced by electrode passivation (precluding the electrosynthesis of useful quantities of $l$-methylene green) and a large "stripping" peak corresponding to the reoxidation of surface-bound $l$-methylene green, Fig. 4b [24,25]. In the presence of power ultrasound alone, there is a larger stripping peak (as mass transport to the electrode is increased) and a decrease in the "steady-state" reduction wave at potentials more negative that $0.23 \mathrm{~V}$ vs. SCE, reflecting electrode passivation occurs even under turbulent conditions, Fig. 4c [24,25].

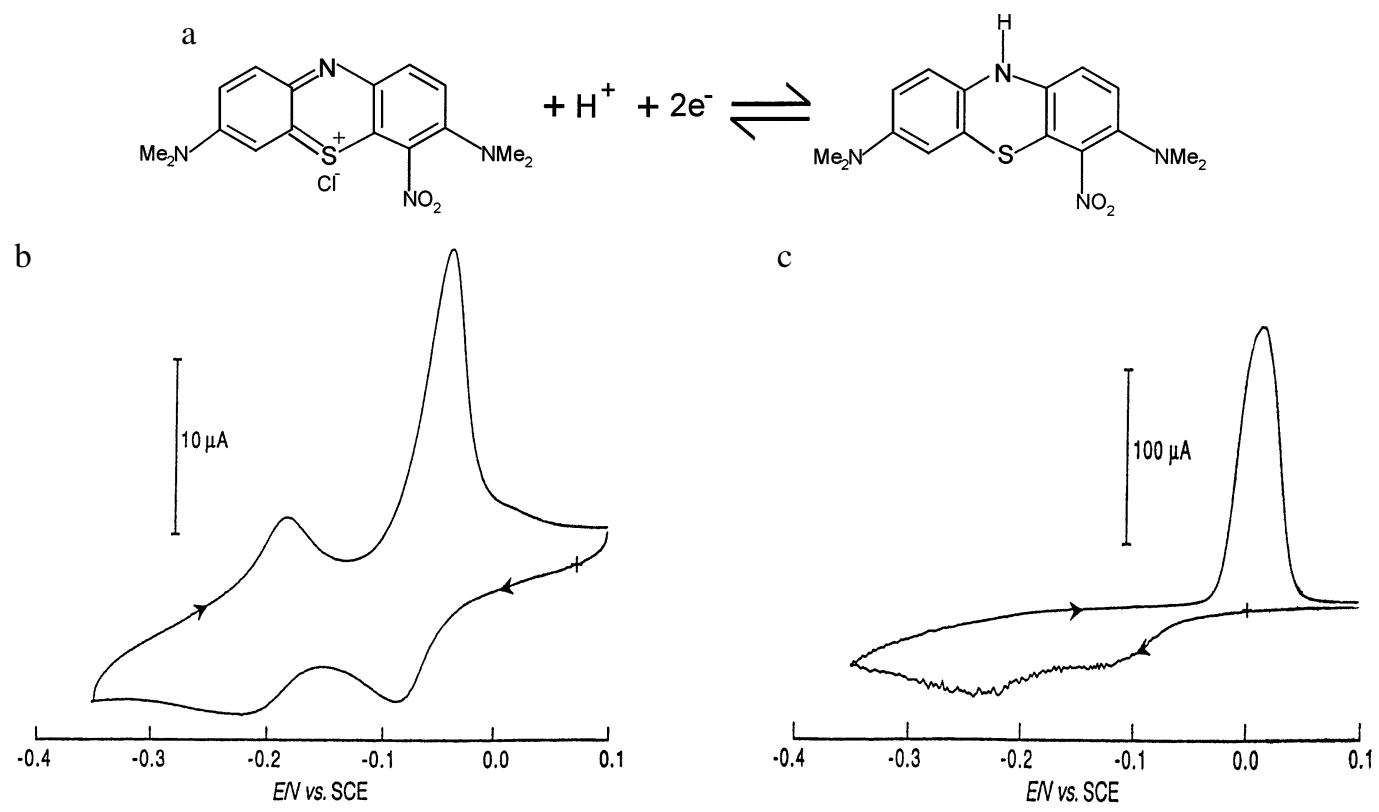

d

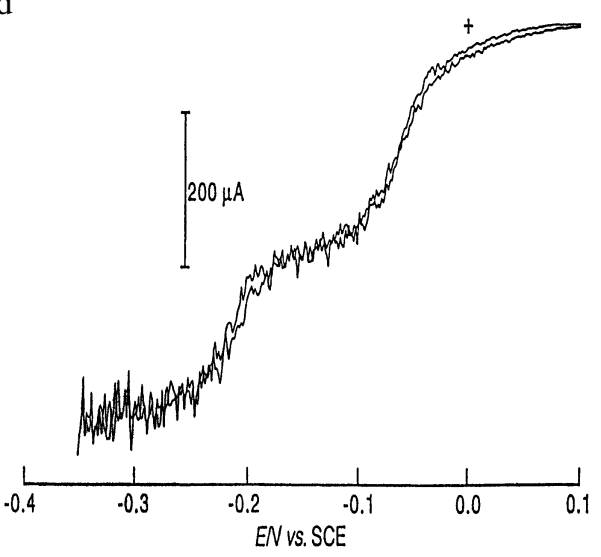

Fig. 4 (a) Scheme for the reduction of methylene green to either solid or aqueous $l$-methylene green.(b) Quiescent voltammogram of $0.2 \mathrm{mM}$ methylene green in $0.1 \mathrm{M} \mathrm{KCl} / 0.2 \mathrm{M} \mathrm{KH}_{2} \mathrm{PO}_{4}$ (aq) at $\mathrm{pH} 6.5$. Scan rate was $10 \mathrm{mV} \mathrm{s}^{-1}$, and the working electrode was a 6-mm-diameter platinum disc. (c) Cyclic voltammogram of $0.2 \mathrm{mM}$ methylene green in $0.1 \mathrm{M} \mathrm{KCl} / 0.2 \mathrm{M} \mathrm{KH}_{2} \mathrm{PO}_{4}(\mathrm{aq})$ at $\mathrm{pH} 6.5 .25 \mathrm{~W} \mathrm{~cm}{ }^{-2}(20 \mathrm{kHz})$ ultrasound was emplyed at a horn-toelectrode separation of $22 \mathrm{~mm}$. Scan rate was $10 \mathrm{mV} \mathrm{s}^{-1}$, and the working electrode was a 6-mm-diameter platinum disc. (d) Cyclic voltammogram of $0.2 \mathrm{mM}$ methylene green in $0.1 \mathrm{M} \mathrm{KCl} / 0.2 \mathrm{M} \mathrm{KH}_{2} \mathrm{PO}_{4}$ (aq) at pH 6.5 and $20 \mathrm{vol}$ $\%$ toluene (emulsified). $18 \mathrm{~W} \mathrm{~cm}^{-2}$ ultrasound was employed at a horn-to-electrode separation of $19 \mathrm{~mm}$. Scan rate was $10 \mathrm{mV} \mathrm{s}^{-1}$, and the working electrode was a 6-mm-diameter platinum disc. 
However, when 20 vol \% of toluene (or $n$-octane) is added to the aqueous electrolyte, two steadystate sigmoidal waves are observed (Fig. 4d) [24,25]; l-methylene green is soluble in the emulsified organic phase, and its formation is evidenced using UV-vis spectrophotometry; a peak observed at $263 \mathrm{~nm}$ corresponds to $l$-methylene green in $n$-octane [49].

The electrosynthesis of water-insoluble products such as $l$-methylene green from soluble precursors has been shown to be achievable using an acoustic emulsion, so that the organic phase constantly extracts the product and simultaneously prevents electrode passivation that would occur in aqueous solution alone.

\section{CONCLUSIONS}

Oil-in-water emulsions formed in situ via application of power ultrasound have shown to provide environmentally friendly environments for electrochemical syntheses. They not only facilitate otherwise impossible electrosyntheses, but additionally permit the occurrence of new reaction mechanisms via encapsulation of the reaction intermediates within the organic component of the emulsion. Furthermore, by prefentially trapping the product formed during the course of electrosysnthesis in the oil phase, electrode depassivation and prolonged electrolysis have been shown to be achievable. This type of electrosynthetic technology shows clear promise for wider application, especially because the major liquid component is water; the use of large quantities of environmentally unfriendly nonaqueous solvents is not necessary for these types of electrosynthesis.

\section{ACKNOWLEDGMENTS}

The authors thank their coworkers and collaborators, Richard Akkermans, Jon Ball, Steve Bull, Javier Del Campo, Steve Davies, Sarah Roberts, Dave Walton, and Shelley Wilkins for their varied and diverse contributions to our electrosynthetic studies. F. M. thanks the Royal Society for a University Research Fellowship. We also thank James Davis and Nathan Lawrence for making the Coimbra conference all the more enjoyable. Further, we thank Jim Rusling for his interest in our "dynamic" emulsions.

\section{REFERENCES}

1. R. G. Compton, F. Marken, J. C. Eklund. Electroanalysis 7, 509 (1997).

2. J. C. Ball and R. G. Compton. Electrochemistry 67, 912 (1999).

3. H. S. Fogler. Chem. Eng. Prog. Symp. Ser. No. 109, 67, 1 (1971).

4. F. Marken and R. P. Akkermans. J. Electroanal. Chem. 415, 55 (1996).

5. W. Le Mars Nyborg. In Physical Acoustics, W. P. Mason (Ed.), p. 265, Academic, New York (1965).

6. T. J. Mason. Sonochemistry, Oxford University Press, Oxford (1999).

7. A. Henglein and M. Gutiérrez. J. Phys. Chem. 97, 11368 (1993).

8. R. G. Compton, J. C. Eklund, S. D. Page, G. H. W. Sanders, J. Booth. J. Phys. Chem. 98, 12410 (1994).

9. A. Benahcene, C. Petrier, G. Reverdy, P. Labre. New J. Chem. 19, 989 (1995).

10. H. Fujiwara, M. Atobe, H. Kanetsuna, T. Nonaka. J. Chin. Chem. Soc. 45, 175 (1998).

11. D. J. Walton, S. S. Phull, U. Geissler, A. Chyla, A. Durham, S. Ryley, T. J. Mason, J. P. Lorrimer. Electrochem. Commun. 2, 431 (2000).

12. J.-L. Luche. Synthetic Organic Sonochemistry, Plenum, New York (1998).

13. D. J. Walton and S. S. Phull. Adv. Sonochem. 4, 205 (1996).

14. F. J. Del Campo, J. L. Hardcastle, R. G. Compton. In Encyclopadia of Electrochemistry, Vol. 2, P. R. Unwin (Ed.), Wiley. In press.

15. J.-L. Luche. Ultrason. Sonochem. 3, S215 (1996). 
16. R. W. Wood and A. L. Loomis. Phil. Mag. 4, 417 (1927).

17. M. K. Li and H. S. Fogler. J. Fluid Mech. 88, 499 (1978).

18. M. K. Li and H. S. Fogler. J. Fluid Mech. 88, 512 (1978).

19. H.-J. Ladwig, H. Oelmann, W. Pippel. Wissen. Z. Techn. Univers. Dresden 39, 163 (1990).

20. B. Abismaill, J. P. Canselier, A. M. Wilhelm, H. Delmas, C. Gourdon. Ultrason. Sonochem. 6, 75 (1999).

21. O. Behrend, K. Ax, H. Schubert. Ultrason. Sonochem. 7, 77 (2000).

22. F. Marken and R. G. Compton. Electrochim. Acta 43, 2157 (1997).

23. F. Marken, R. G. Compton, S. D. Bull, S. G. Davies. Chem. Commun. 995 (1997).

24. R. P. Akkermans, S. L. Roberts, R. G. Compton. Chem. Commun. 1115 (1999).

25. R. P. Akkermans, S. L. Roberts, F. Marken, B. A. Coles, S. J. Wilkins, J. A. Cooper, K. E. Woodhouse, R. G. Compton. J. Phys. Chem. B 103, 9987 (1999).

26. J. D. Wadhawan, F. Marken, R. G. Compton, S. D. Bull, S. G. Davies. Chem. Commun. 87 (2001).

27. J. D. Wadhawan, F. J. Del Campo, R. G. Compton, J. S. Foord, F. Marken, S. D. Bull, S. G. Davies, D. J. Walton, S. Ryley. J. Electroanal. Chem. 507, 135 (2001).

28. A. N. Blythe, R. P. Akkermans, R. G. Compton. Electroanalysis 12, 16 (2000).

29. J. L. Hardcastle, C. J. Paterson, R. G. Compton. Electroanalysis 13, 899 (2001).

30. J. L. Hardcastle and R. G. Compton. Analyst 126, 2023 (2001).

31. J. L. Hardcastle and R. G. Compton. Electroanalysis (2002). In press.

32. J. Gao, J. F. Rusling, D.-L. Zhou. J. Org. Chem. 61, 5972 (1996).

33. J. F. Rusling and D.-L. Zhou. J. Electroanal. Chem. 439, 89 (1997).

34. J. Gao, C. K. Njue, J. K. N. Mbindyo, J. F. Rusling. J. Electroanal. Chem. 464, 31 (1999).

35. R. A. Mackay and J. Texter (Eds.). Electrochemistry in Colloids and Dispersions, VCH, Weinheim (1992).

36. H. Feess and H. Wendt. In Techniques of Electro-organic Synthesis, N. L. Weinberg and B. V. Tilak (Eds.), Part III, p. 81 ff, Wiley, New York (1982).

37. H. Huck. Ber. Beunsenges. Phys. Chem. 91, 648 (1987).

38. C. R. S. Hagan and L. A. Coury, Jr. Anal. Chem. 66, 399 (1994).

39. P. R. Birkin and S. Silva-Martinez. J. Chem. Soc., Chem. Commun. 1807 (1995).

40. T. G. Leighton. The Acoustic Bubble, p. 531, Academic, London (1994).

41. A. J. Bard, V. J. Puglisi, J. V. Kenkel, A. Lomax. Faraday Discuss. 56, 353 (1973).

42. C. R. Wilke and P. Chang. AIChE J. 1, 264 (1955).

43. C. J. Brockman. Electro-organic Chemistry, Wiley, New York (1926).

44. S. Torii and H. Tanaka. In Organic Electrochemistry, M. Bazier (Ed.), Marcel Dekker, New York (1991).

45. D. Pletcher and F. C. Walsh. Industrial Electrochemistry, $2^{\text {nd }}$ ed., Chapman and Hall, London (1990).

46. Q. Chi and S. Dong. Anal. Chim. Acta 285, 125 (1994).

47. Y. Zhu and S. Dong. Electrochim. Acta 35, 1139 (1990).

48. D.-M. Zhou, H.-Q. Fang, H.-Y. Chen, H.-X. Ju, Y. Wang. Anal. Chim. Acta 329, 41 (1996).

49. A. T. Vartanyan. Opt. Spektrosk. 1, 478 (1956). 